\title{
Desempenho de genótipos de coentro em Areia
}

\author{
Ademar P de Oliveira ${ }^{1,6}$; Paulo César T. de Melo²; Luiz Jorge da G Wanderley Júnior ${ }^{3}$; Anarlete U Alves ${ }^{4}$; \\ Macio F de Moura ${ }^{5}$; Arnaldo Nonato P de Oliveira ${ }^{4}$ \\ ${ }^{1}$ UFPB, CCA, C. Postal 02, 58397-000 Areia-PB; ${ }^{2}$ USP-ESALQ Depto. Produção Vegetal, C. Postal 09, 13418-900 Piracicaba-SP; \\ ${ }^{3}$ Hortivale, Rua Valdomiro R. de Andrade, 103, Matriz, 55612-612 Vitória de Santo Antão-PE; ${ }^{4}$ Estudante agronomia; ${ }^{5}$ Pós-graduando \\ em agronomia; ${ }^{6}$ bolsista CNPq; ademar@cca.ufpb.br
}

\section{RESUMO}

Avaliaram-se sete genótipos de coentro, sendo cinco linhagens (HTV 9299, HTV 7299, HTV 0699, HTV 0999 e HTV 0199) e duas cultivares comerciais (Verdão e Palmeira), de maio a julho de 2003 no município de Areia-PB, em delineamento de blocos casualizados em quatro repetições. As cultivares Verdão $\left(5,0 \mathrm{~kg} \mathrm{~m}^{-2}\right)$ e Palmeira $\left(4,3 \mathrm{~kg} \mathrm{~m}^{-2}\right)$ e as linhagens HTV $9299\left(4,4 \mathrm{~kg} \mathrm{~m}^{-2}\right)$, HTV $7299(4,5$ $\left.\mathrm{kg} \mathrm{m}^{-2}\right)$ e HTV $0999\left(4,3 \mathrm{~kg} \mathrm{~m}^{-2}\right)$, apresentaram as maiores produções de massa verde (PMV), enquanto a linhagem HTV 0199, com produção de $2,9 \mathrm{~kg} \mathrm{~m}^{-2}$, foi a menos produtiva. As linhagens HTV $7299(0,73)$ e HTV $0199(0,81)$ apresentaram os mais elevados valores para a relação folhas:talos. As cultivares Verdão e Palmeira e as linhagens HTV 7299, HTV 0999, HTV 0699 e 9299 apresentaram $65 ; 58 ; 35 ; 29 ; 40$ e $59 \%$, respectivamente, de plantas pendoadas aos 42 dias após a semeadura, enquanto a linhagem 0199 apresentou apenas $11 \%$. A linhagem HTV 7299 pode ser uma alternativa para os produtores de coentro da região de Areia.

Palavras-chave: Coriandrum sativum L., genótipos, plantas pendoadas, produção de massa verde.

\begin{abstract}
Performance of coriander genotypes in the municipality of Areia

Seven coriander genotypes were evaluated (lines HTV 9299, HTV 7299, HTV 0699, HTV 0999,HTV 0199 and cvs. Verdão and Palmeira), in Areia County, Paraiba State, Brazil, from May to July of 2003 in randomized blocks in four replications. Verdão $\left(5,0 \mathrm{~kg} \mathrm{~m}^{-}\right.$ $\left.{ }^{2}\right)$ and Palmeira $\left(4,3 \mathrm{~kg} \mathrm{~m}^{-2}\right)$ cultivars and the lines HTV $9299(4,4$ $\left.\mathrm{kg} \mathrm{m}^{-2}\right)$, HTV $7299\left(4,5 \mathrm{~kg} \mathrm{~m}^{-2}\right)$ and HTV $0999\left(4,3 \mathrm{~kg} \mathrm{~m}^{-2}\right)$, exhibited the greatest yield of green mass (GM), while the line HTV 0199, with $2.9 \mathrm{~kg} \mathrm{~m}^{-2}$ of GM, showed the lowest yield. Lines HTV 7299 (0.73) and HTV 0199 (0.81) presented the largest values for the ratio leaves:stalks. Verdão and Palmeira cultivars and lines HTV 7299, HTV 0999, HTV 0699 and 9299 persented 65; 58; 35; 29; 40 and $59 \%$, respectively, of plant bolting (PB) at 42 days after sowing date, while Line HTV 0199 presented only 11\%. Line HTV 7299 might be an alternative for coriander cropping in Areia.
\end{abstract}

Keywords: Coriandrum sativum L., genotypes, plants bolting, green mass yield.

\section{(Recebido para publicação em 29 de abril de 2006; aceito em 22 de maio de 2007)}

$\mathrm{O}$ coentro (Coriandrum sativum L.) é uma hortaliça herbácea anual pertencente à família Apiaceae, nativa da bacia do Mar Mediterrâneo. Devido à versatilidade de uso, é uma olerácea de considerável valor e importância sócio-econômica mundial, em especial, na Ásia, onde se localizam os países líderes de produção e consumo (Diederichsen, 1996). Seu cultivo visa a produção de massa verde fresca, enquanto os frutos secos (sementes) são largamente utilizados na indústria de condimento, sendo o principal ingrediente do "curry", tempero muito utilizado nas culinárias hindu e tailandesa. Alguns tipos varietais específicos são utilizados para extração de óleos essenciais de alto valor agregado, largamente empregados nas indústrias de flavorizantes, comésticos, medicamentos e de bebidas (Rangahau, 2001).

No Brasil, o coentro é a hortaliça folhosa condimentar de maior consumo, muito utilizada na culinária típica regional, especialmente nas regiões Norte e
Nordeste (Pedrosa et al., 1984; Marques \& Lorencetti, 1999). No estado da Paraíba, é cultivado em quase todas as micro-regiões por pequenos agricultores, sem nenhuma orientação técnica, o que tem proporcionado baixa produtividade, principalmente devido à falta de cultivares mais adaptadas às diferentes zonas de cultivo.

Existem no mercado brasileiro cultivares de coentro de boa aceitação comercial, entretanto, não há um programa regional de avaliação de genótipos visando identificar e recomendar aqueles de melhor adaptação às diversas condições agroecológicas das zonas de cultivo. A identificação de cultivares adaptadas e com maior potencial produtivo, proporciona maior segurança aos produtores sendo, ainda, uma informação que poderá facilitar a obtenção de crédito e aceitação do produto no mercado consumidor (HamasakI et al., 1998).

No Brasil, pouca pesquisa tem sido feita com o coentro, incluindo a tecnologia adequada para a produção e desenvolvimento de novas cultivares (Pereira et al., 2005). Soma-se a isso escassez de trabalhos de melhoramento genético com a espécie, e as cultivares hoje disponíveis estão sendo utilizadas nas diversas regiões geográficas, sem se considerar as suas possíveis diferenças de comportamento nos diversos ambientes (Wanderley Júnior $\&$ Melo, 2003). Por este fato, torna-se importante a condução de experimentos regionais visando estudar o comportamento de novos materiais. Esses estudos constituem importante ferramenta a ser utilizada na recomendação de cultivares e fornece subsídios para novos programas de melhoramento genético. Também, a identificação de genótipos estáveis, que possam ser utilizados em diferentes zonas de cultivo e épocas de plantio, é interessante para as empresas do setor de sementes e produtores (Alvarez \& Curione, 1993; Peixoto et al., 1993).

Este trabalho teve como objetivo avaliar o comportamento de novas linhagens 
de coentro em comparação com as cultivares existentes no mercado, nas condições edafoclimáticas de Areia (PB).

\section{MATERIAL E MÉTODOS}

O experimento foi conduzido de maio a julho de 2003, na UFPB, em Areia, localizada a $6^{\circ} 18^{\prime} 12^{\prime \prime} \mathrm{S}$ e $32^{\circ}$ $18^{\prime} 15^{\prime \prime} \mathrm{W}$, em altitude de $560 \mathrm{~m}$. O clima é do tipo As' segundo Köppen, quente e úmido, com precipitação média anual de $1400 \mathrm{~mm}$ (Brasil, 1972). A temperatura média $\left({ }^{\circ} \mathrm{C}\right)$, a precipitação pluviométrica $(\mathrm{mm})$ e a umidade relativa $(\%)$ do período de execução do experimento foram, respectivamente: maio $=21,8 ; 147,2 ; 90$, junho $=19,1 ; 136,9$, 90 e julho $=18,9 ; 192,4 ; 88$.

O solo utilizado foi classificado como NEOSSOLO REGOLÍTICO psamítico típico (Embrapa, 1999), de textura areia-franca, com as características química e física: $\mathrm{pH}\left(\mathrm{H}_{2} \mathrm{O}\right)=6,30$; $\mathrm{P}$ disponível $=21,80 \mathrm{mg} \mathrm{dm}^{-3} ; \mathrm{K}=34,19$ $\mathrm{mg} \mathrm{dm}{ }^{-3} ; \mathrm{Ca}^{+2}+\mathrm{Mg}=3,95 \mathrm{cmol}_{\mathrm{c}} \mathrm{dm}^{-3}$; $\mathrm{H}+\mathrm{Al}$ trocável $=0,0 \mathrm{cmol}_{\mathrm{c}} \mathrm{dm}^{-3} \mathrm{e} \mathrm{ma}$ téria orgânica $=11,3 \mathrm{~kg} \mathrm{dm}^{-3}$; areia $=$ $841,50 \mathrm{~g} \mathrm{~kg}^{-1}$; silte $=88,00 \mathrm{~g} \mathrm{~kg}^{-1}$; argila $=70,50 \mathrm{~g} \mathrm{~kg}^{-1} ;$ densidade do solo $=1,37$ $\mathrm{kg} \mathrm{dm}^{-3}$; densidade de partículas $=2,61$ $\mathrm{g} \mathrm{dm}^{-3}$ e porosidade total $=0,47 \mathrm{~m}^{3} \mathrm{~m}^{-3}$.

Foram avaliadas duas cultivares comerciais (Verdão e Palmeira) e cinco linhagens (HTV 9299, HTV 7299, HTV 0699, HTV 0999 e HTV 0199) de coentro, obtidas pelo programa de melhoramento genético da empresa Hortivale Sementes do Vale Ltda localizada em Vitória de Santo Antão (PE), em delineamento experimental de blocos casualizados, com quatro repetições. As parcelas mediram $4,0 \mathrm{~m}^{2}$, com um metro de largura e quatro de comprimento, contendo 266 plantas, sendo todas consideradas úteis.

A adubação seguiu recomendações do Laboratório de Química e Fertilidade de Solos da UFPB e constou da aplicação $5,0 \mathrm{~kg} \mathrm{~m}^{-2}$ de esterco bovino curtido e seco, $15,0 \mathrm{~g} \mathrm{~m}^{-2}$ de cloreto de potássio e de $56 \mathrm{~g} \mathrm{~m}^{2}$ de superfosfato simples, aplicadas cinco dias antes da semeadura, e de $25 \mathrm{~g} \mathrm{~m}^{2}$ de uréia, fornecido em adubação de cobertura, parcelado $50 \%$ aos 20 e $50 \%$ aos 40 dias após a semeadura (DAS).

Tabela 1. Produção de massa verde (PMV) e relação folhas:talos (RFT) em cultivares e linhagens de coentro, nas condições de Areia-PB. (Yield green mass (YGM), and leaves:talks (LT) in the lines and cultivars of coriander in Areia-PB, Brazil, conditions). Areia, CCAUFPB, 2003.

\begin{tabular}{lcc}
\hline Genótipos & PMV $\left(\mathbf{k g ~ m}^{-2}\right)$ & RTF \\
\hline Verdão & $5,0 \mathrm{a}$ & $0,54 \mathrm{~b}$ \\
Palmeira & $4,3 \mathrm{a}$ & $0,60 \mathrm{~b}$ \\
HTV - 9299 & $4,4 \mathrm{a}$ & $0,50 \mathrm{~b}$ \\
HTV - 7299 & $4,5 \mathrm{a}$ & $0,73 \mathrm{a}$ \\
HTV - 0699 & $3,5 \mathrm{~b}$ & $0,64 \mathrm{~b}$ \\
HTV - 0999 & $4,3 \mathrm{a}$ & $0,63 \mathrm{~b}$ \\
HTV - 0199 & $2,9 \mathrm{c}$ & $0,81 \mathrm{a}$ \\
\hline CV (\%) & 12 & 16 \\
\hline
\end{tabular}

Médias seguidas da mesma letra, na coluna, não diferem entre si pelo teste Scott-Knott a 5\% de probabilidade. (Means with the same latter in the columns do not differ at 0.05 level of probability, by Scott-Knott test)

O preparo do solo constou da confecções de canteiros e abertura de sulcos de plantio. As sementes foram distribuídas em sulcos longitudinais, distanciados de $25 \mathrm{~cm}$ a uma profundidade de $3,0 \mathrm{~cm}$, realizando-se o desbaste vinte dias depois, deixando-se uma planta a cada $5,0 \mathrm{~cm}$. Durante a execução do experimento realizaram-se os tratos culturais normais para a cultura, incluindo irrigação por aspersão nos períodos de ausência de precipitações, onde todos os genótipos receberam a mesma lâmina de água, e capinas manuais. Não se utilizou defensivos agrícolas, devido à baixa incidência de pragas e doenças.

Foram avaliados a produção de massa verde (PMV), relação folhas:talos (RFT) e percentagem de pendoamento (PP) aos 42; 49; 56 e 63 DAS. A PMV foi determinada aos 42 DAS, e correspondeu ao peso de talos e folhas de 133 plantas de cada parcela. Por ocasião da avaliação da PMV, foi determinada a RFT. Para tanto, em amostra de $100 \mathrm{~g}$ de massa verde por tratamento, foram separadas as folhas e talhos e pesados isoladamente; o PP foi obtido pela relação entre o número de plantas que emitiam pendão floral em cada período pré-estabelecido e o número total de plantas (266).

Os resultados foram submetidos às análises de variância, sendo as somas dos quadrados médios comparadas pelo teste F (5\%). Para comparação das médias da PMV e RTF (características qualitativas), foi empregado o teste ScottKnott, a 5\% de probabilidade; enquanto as médias do PP foram submetidas a análises de regressão.

\section{RESULTADOS E DISCUSSÃO}

Houve efeito significativo $(\mathrm{p}<0,05)$ dos genótipos para a produção de massa verde (PMV), relação folhas:talos (RFT) e para a percentagem de pendoamento (PP), em todos os períodos de avaliação. As cultivares Verdão e Palmeira e as linhagens HTV 9299, HTV 7299 e HTV 0999, apresentaram as mais elevadas produções de massa verde (PMV), seguida da linhagem HTV 0699. A linhagem HTV 0199 foi responsável pelo mais baixo valor para essa característica (Tabela 1). Nas condições de Passo Fundo (RS), Marques \& Lorencetti (1999), também verificaram superioridade da cultivar Verdão na produção de massa verde, em relação a outros genótipos avaliados, porém com rendimento muito baixo $\left(2,4 \mathrm{~kg} \mathrm{~m}^{2}\right)$.

$\mathrm{O}$ rendimento de massa verde obtido pelas cultivares Verdão e Palmeira e pelas linhagens HTV 9299, HTV 7299, e HTV 0999 foram superiores ao rendimento médio de massa verde definido para o estado de Pernambuco em 4,0 kg $\mathrm{m}^{-2}$ (Hortivale, 1987), o que pode indicar que esses genótipos são os mais promissores para a produção de massa verde, na região de Areia.

Quanto à relação folhas:talos (RFT), igualmente à PMV, também apresentou variação significativa entre os genótipos, indicando que a formação de folhas é um atributo genético de cada genótipo. No entanto, as linhagens HTV 7299 e HTV 0199 apresentaram os mais 


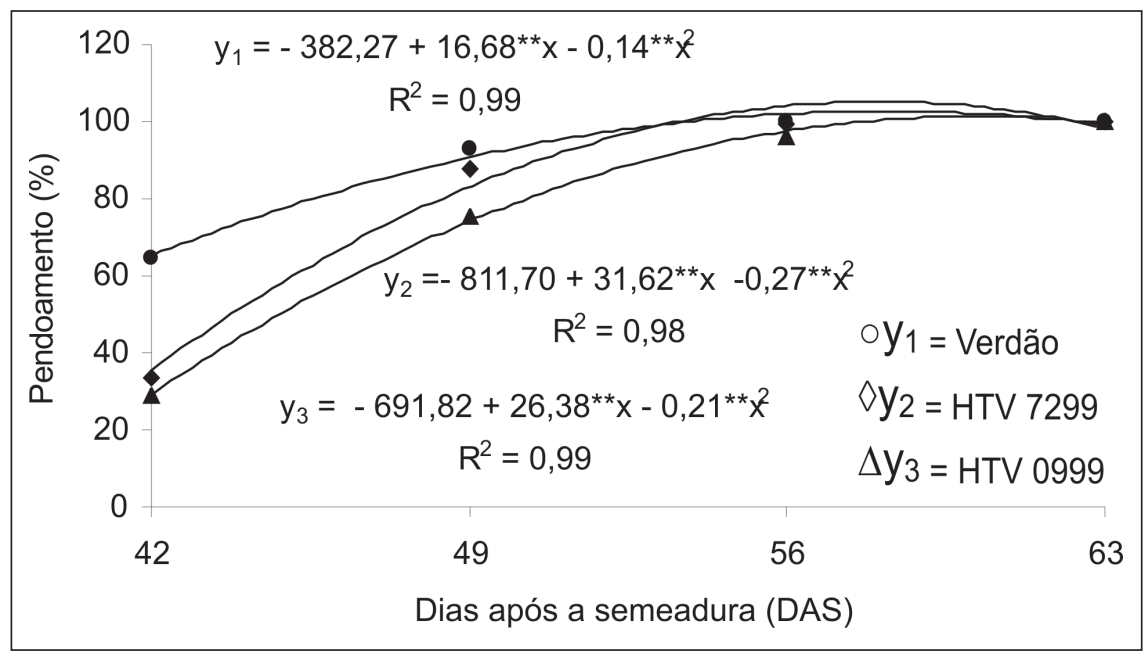

Figura 1. Percentagem de pendoamento em coentro, cultivar Verdão $\left(\mathrm{y}_{1}\right)$ e linhagens HTV $7299\left(\mathrm{y}_{2}\right)$ e HTV $0999\left(\mathrm{y}_{3}\right)$, em função de idades de plantas. (Plants bolting percent in the coriander, Verdão $\left(\mathrm{y}_{1}\right)$ cultivar and lines HTV $7299\left(\mathrm{y}_{2}\right)$ and $\operatorname{HTV} 0999\left(\mathrm{y}_{3}\right)$, as a function of plant age). Areia, CCA-UFPB, 2003.

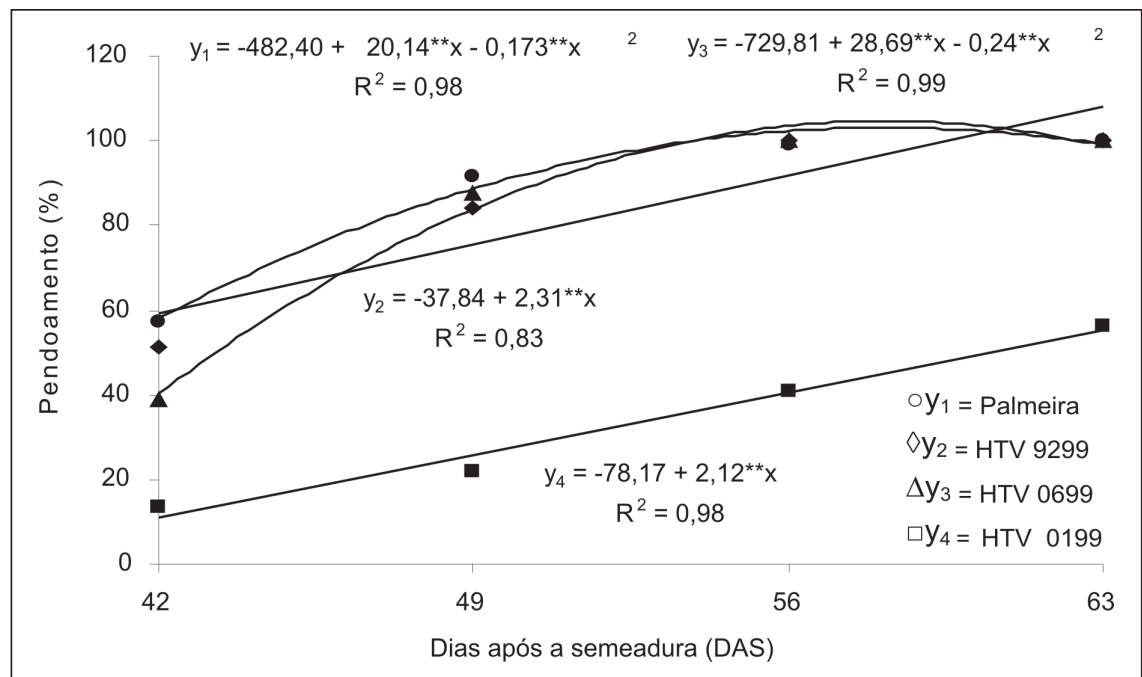

Figura 2. Percentagem de pendoamento em coentro, cultivar Palmeira $\left(\mathrm{y}_{1}\right)$ e linhagens HTV $9299\left(\mathrm{y}_{2}\right)$, HTV $0699\left(\mathrm{y}_{3}\right)$ e HTV $0199\left(\mathrm{y}_{4}\right)$, em função de idades de plantas. (Plants bolting percent in the coriander, Palmeira $\left(\mathrm{y}_{1}\right)$ cultivar and lines HTV $9299\left(\mathrm{y}_{2}\right)$, HTV $0699\left(\mathrm{y}_{3}\right)$ and HTV $0199\left(\mathrm{y}_{4}\right)$, as a function of plant age). Areia, CCA-UFPB, 2003.

elevados valores para essa relação, diferindo significativamente das cultivares Verdão e Palmeira e das linhagens HTV 9299, HTV 0699 e HTV 0999. Os valores de RTF obtidos palas linhagens HTV 7299 e HTV 0199 mostram um potencial comercial. Os demais se caracterizaram como genótipos com elevados percentuais de talos, reduzindo a sua qualidade comercial (Tabela 1). Nas condições de Passo Fundo a cultivar Verdão apresentou relação folhas:talos muito baixa, de 0,40 (Marques \& Lorencetti, 1999).

Para a percentagem de pendoamento (PP), as medias das cultivares Verdão e
Palmeira e das linhagens HTV 7299, HTV 0999 e HTV 0699, ajustaram-se a modelos quadráticos de regressão em função dos períodos de avaliações (Figuras 1 e 2). Por meio das derivadas das equações de regressões, calcularam-se o período estimado de 58 DAS como aquele responsável por mais de $100 \%$ de plantas pendoadas nas cultivares Verdão e Palmeira e nas linhagens HTV 7299 e HTV 0699; enquanto que na linhagem HTV 0999 esse percentual foi alcançado aos 60 DAS. Nas linhagens HTV 9299 e HTV 0199, o pendoamento aumentou de forma linear em função dos períodos de avaliações, com mais de $100 \%$ de plantas pendoadas aos 63 DAS na linhagem HTV 9299 e apenas 55\% na linhagem HTV 0199. Aos 42 (DAS) (período recomendado para a colheita do coentro), as cultivares Verdão e Palmeira e as linhagens HTV 7299, HTV 0999, HTV 0699 e 9299, apresentaram pendoamento estimado de $65 ; 58 ; 35$; 29; 40 e $59 \%$, respectivamente, enquanto a linhagem 0199 apresentou apenas $11 \%$ das plantas com pendões florais.

Temperaturas acima do nível ótimo podem acelerar o florescimento de certas hortaliças (Filgueira, 2003). A temperatura média acima de $25^{\circ} \mathrm{C}$ favorece a produção de sementes de coentro (Diederichsen, 1996), e consequentemente o pendoamento. Como a temperatura média do período de execução do trabalho foi de $20^{\circ} \mathrm{C}$, os percentuais de pendoamentos obtidos nos genótipos, podem ser atribuídos às suas características genéticas.

O pendoamento precoce no coentro é uma característica prejudicial quando o objetivo é a comercialização de massa verde, pois reduz o número de folhas em detrimento da formação de pendões florais. Portanto, os genótipos com menores percentuais de pendoamento são considerados de boa qualidade.

As características PMV, RFT e PP são parâmetros importantes para determinar a qualidade comercial do coentro. Portanto, as linhagens HTV 7299 e HTV 0999, que exibiram PMV superior a 4,0 $\mathrm{kg} \mathrm{m}^{-2}$, RFT igual a 0,73 e 0,63 , e PP de 35 e $29 \%$, respectivamente, aos 42 DAS podem ser consideradas como alternativas para os produtores de coentro da região de Areia. Por sua vez, a linhagem HTV 0199 embora tenha apresentado maior valor para RFT e menor PP em todos os períodos de avaliação, mostrou baixo potencial de rendimento de massa verde. Esse fato demonstra que a mesma não pode ser considerada uma alternativa de cultivo em Areia.

\section{AGRADECIMENTOS}

Os autores agradecem aos agentes em Agropecuária, Francisco de Castro Azevedo, José Barbosa de Souza, Francisco Soares de Brito, Francisco Silva do Nascimento e Expedito de Souza 
Lima que viabilizaram a execução dos trabalhos de campo.

\section{REFERÊNCIAS}

ALVAREZ A; CURIONI A. 1993. Efecto de dos épocas de siembra sobre el rendimiento y la producción de biomassa en coriandro (Coriandrum sativum L.). Anales SAIPA 11: 211-215.

BRASIL. 1972. Ministério da Agricultura. Levantamento exploratório, reconhecimento de solos do Estado da Paraíba. Rio de Janeiro: MA CONTAP/USAIO/SUDENE, 670 p. (Boletim técnico, 15).

DIEDERICHSEN A. 1996. Coriander (Coriandrum sativum $L$.). promoting the conservation and use of underutilized and negleted crops. 3. Rome: Institute of Plant Genetics and Crop Plant Research, Gatersleben/International Plant Genetic Resources Institute. 83 p.
EMBRAPA. 1999. Centro Nacional de Pesquisa de Solos. Sistema brasileiro de classificação de solos. Brasília - SPI - EMBRAPA. 412 p.

FILGUEIRA FAR. 2003. Novo Manual de Olericultura: Agrotecnologia moderna na produção e comercialização de hortaliças. 2. Ed. Viçosa: UFV. 412 p.

HAMASAKI RI; BRAZ LT; PURQUERIO LFV; PEIXOTO N. 1998. Comportamento de novas cultivares de feijão-vagem em JaboticabalSP. In: CONGRESSO BRASILEIRO DE OLERICULTURA, 38. 1998, Petrolina. Resumo... Petrolina: SOB.

HORTIVALE. 1987. Sementes de coentro Verdão: informativo ao agricultor. Vitória de Santo Antão, 2 p (Boletim informativo).

MARQUES FC; LORENCETTI BL. 1999. Avaliação de três cultivares de coentro (Coriandrum sativum L.) semeadas em duas épocas. Pesquisa Agropecuária Gaúcha 5: 265-270.

PEDROSA FS; NEGREIROS MZ; NOGUEIRA ICC. 1984. Aspectos da cultura do coentro. Informe Agropecuário 10: 75-78.
PEIXOTO N; SILVA LO; THUNG MDT; SANTOS G. 1993. Produção de sementes de linhagens e cultivares arbustivas de feijão-vagem em Anápolis. Horticultura Brasileira 11: 151152.

PEREIRA RS; MUNIZ MFB; NASCIMENTO WM. 2005. Aspectos relacionados à qualidade de sementes de coentro. Horticultura Brasileira 23: 703-706.

RANGAHAU MK. Coriander. Crop \& food research [Broad sheet], n. 30, March 2001. 4 p. Disponível em: http. www:nzicfr.com.nz. Acesso em: 07 de agosto de /2004.

WANDERLEY JÚNIOR LJG; MELO PCT. 2003. Tapacurá: nova cultivar de coentro adaptada às condições subtropicais do Brasil. In: CONGRESSO BRASILEIRO DE OLERICULTURA, 43, Recife. Anais... Recife, SOB, CD-Rom. 